\title{
3 WBW 2015: t9 Breastfeeding and Work Let's make it Work!
}

\section{B H N Yasmeen ${ }^{1}$}

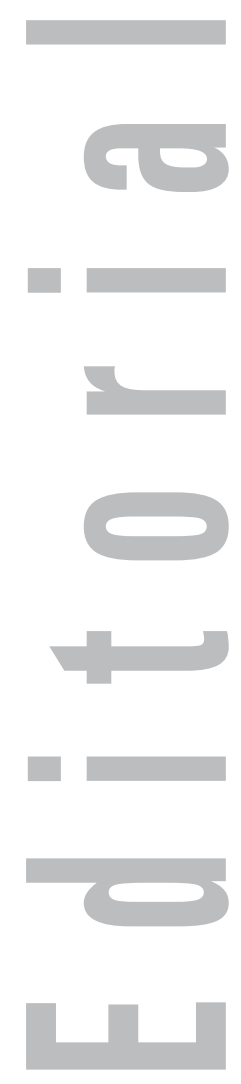

1 Prof. Dr. B H Nazma Yasmeen MBBS, MCPS, MD (Paed) Editor Northern International Medical College

Professor \& Head Dept. of Paediatrics Northern International Medical College, Dhaka email :

prof.nazma.yasmeen@gmail.com
World Breastfeeding Week (WBW) is celebrated every year from 1 to 7 August in more than 170 countries to encourage breastfeeding and improve the health of babies around the world. Twenty five years ago, the World Alliance for Breastfeeding Action (WABA) launched its first World Breastfeeding Week- Campaign with the theme: 'Baby Friendly Hospital Initiative.' This year marks the 25th Anniversary of the Innocenti Declaration 1990 which has been a landmark guiding document for improving breastfeeding practices worldwide. On that declaration four targets were adopted, with the fourth target aiming "to enact imaginative legislation protecting the breastfeeding rights of working women and establish means for its enforcement," still needing much more attention after over 20 years. The WBW 2015 theme on working women and breastfeeding revisits the 1993 WBW campaign on the Mother-Friendly Workplace initiative.

This year also given emphasis on working women and the theme of World Breastfeeding Week is 'Breastfeeding and Work. Let's make it work!'. Much has been achieved in 22 years of global action supporting women in combining breastfeeding and work, particularly the adoption of the revised ILO Convention 183 on Maternity Protection with much stronger maternity entitlements, and more country actions on improving national laws and practices. Yet, after over 20 years, global monitoring on infant and young child feeding progress shows that the fourth Innocenti target is still the most difficult to meet! With the WBW 2015 campaign WABA and its partners at global, regional and national levels aim to empower and support all women, working in both the formal and informal sectors, to adequately combine work with child-rearing, particularly breastfeeding.

\section{WBW 2015: Objectives of WABA}

1. Galvanise multi-dimensional support from all sectors to enable women everywhere to work and breastfeed.

2. Promote actions by employers to become
Family/Parent/Baby and Mother-Friendly, and to actively facilitate and support employed women to continue breastfeeding.

3. Inform people about the latest in global Maternity Protection entitlements, and raise awareness of the need to strengthen related national legislation and implementation.

4. Strengthen, facilitate and showcase supportive practices that enable women working in the informal sector to breastfeed.

5. Engage with target groups e.g. with Trade Unions, Workers Rights Organizations, Women's groups and Youth groups, to protect the breastfeeding rights of women in the workplace.

It is estimated that greater than a million babies could be saved globally per year through breastfeeding. ${ }^{1}$ An exclusively breastfed child is 14 times less likely to die in the first six months than a non-breastfed child, and breastfeeding drastically reduces deaths from acute respiratory infection and diarrhoea, two major child killers (Lancet 2008). Optimal breastfeeding of infants under two years of age has the greatest potential impact on child survival of all preventive interventions, with the potential to prevent over 800,000 deaths (13 $\%$ of all deaths) in children under five in the developing world (Lancet 2013).

The breast milk has long-chain polyunsaturated fatty acids which help in normal retinal and neural development. ${ }^{2}$ It also lower the risk of asthma, food allergies, celiac disease, type 1 diabetes, and leukemia. ${ }^{1}$ Breast milk contains bile salt stimulated lipase and lactoferrin which inhibits the growth of intestinal bacteria. ${ }^{3,4}$ It reduces the risk of postpartum haemorrhage, causes rapid involution of uterus, weight loss, and less postpartum depression. Also decreases the risk of breast cancer, cardiovascular disease, and rheumatoid arthritis of mother. ${ }^{1,5}$ Hormones released during breastfeeding help to strengthen the maternal bond with the baby. ${ }^{6}$ There are many more benefits of breast milk remaining. ${ }^{1-6}$ 
Therefore the potential impact of optimal breastfeeding practices is especially important in developing country situations with a high burden of diseases and low access to clean water and sanitation. In developing countries,there are some barriers that have resulted in poor up take of breastfeeding - range from; a shortage of trained health workers to help educate and guide new mothers, cultural beliefs and absence of/ implementation of maternity protection laws and regulations.

There are approximately 830 million women workers in the world. Many of them return to work soon after delivering babies, and they need supportive national polices and legislation-such as paid maternity leave and breastfeeding breaks-to enable them to continue breastfeeding.There are also millions more women working in the informal, seasonal or part-time economy who face even greater barriers to breastfeeding. They face many challenges in the workplace, least of which is finding space, time and support to breastfeed. Therefore they need strong family and community support to manage the demands of work and breastfeeding their babies. This year, World Breastfeeding Week placing the spotlight on these challenges and supporting and empowering all working women who breastfeed. WABA advocate the following 'elements of support' for successful breastfeeding of a working women.

\section{Elements of Support ${ }^{7}$}

Whether you are claiming your right to breastfeed, or campaigning to support women to work and breastfeed, there are three necessary factors that determine success: TIME, SPACE and SUPPORT. All three factors are needed for women in any kind of work setting.

\section{Time}

1. Six months paid maternity leave post-natally to support exclusive breastfeeding and, adequate paid leave prenatally. Where leave is shorter, women need means to extend their leave period so that they can be with their babies. Combining fully paid, unpaid or some other form of leave.

2. Additional paid leave for mothers of premature or other vulnerable infants who may need extra time for special care, and to express and provide life-saving human milk for their babies.

3. One or more paid breastfeeding breaks or a daily reduction of hours of work to breastfeed her child.

4. Flexible work hours to breastfeed or to express breastmilk such as part-time work schedules, longer lunch and other breaks, job sharing or any such alternatives.

\section{Space / Proximity}

1. Infant and child-care at or near the workplace, and transportation for mothers to be with their babies. For rural worksites and seasonal work, women could use mobile childcare units or shared child care and wet nursing arrangements according to accepted cultural practices.

2. Private facilities for expressing and storing breastmilk. It can be a breastfeeding room, a corner or any safe space at or near the worksite.

3. A clean work environment safe from hazardous waste and chemicals.

\section{Support}

1. Information about national maternity laws and benefits - as well as maternity provisions provided at their workplace or sectorwide - which may be better than national laws and practices.

2. Support from employers, management, superiors and co-workers in terms of positive attitudes towards pregnancy, motherhood and breastfeeding in public.

3. Information about women's health during pregnancy and lactation in order to be better able to combine employment with breastfeeding and child care needs.

4. Support from worker's or trade unions either from their own work sector or the larger national unions.

5. Job security and non-discrimination on the grounds of maternity and breastfeeding.

Virtually every mother can breastfeed, if given appropriate support, advice and encouragement, as well as practical assistance to resolve any problems. Otherwise different challenges and pressures often lead them to stop exclusive breastfeeding early. Teaching partners how to manage common difficulties is associated with higher breastfeeding rates. ${ }^{8}$ Support for a breastfeeding mother can strengthen family bonds and also help to build a paternal bond. ${ }^{6,8}$

Working mothers need support, including legislative measures, to enable them to continue breastfeeding. WBW 2015 hasencouraged us to work more and more on these. Ultimately by which we could take a strong part toreduce the infant death, childhood illness and non-communicable diseases as well as to protect the maternal health.

\section{References}

1. Gartner LM, Morton J, Lawrence RA, Naylor AJ, O'Hare D, Schanler RJ, Eidelman AI. American Academy of Pediatrics Section on Breastfeeding. (March 2012). "Breastfeeding and the use of human milk". Pediatrics129 (3): 827-841. doi:10.1542/peds.2011-3552. PMID 22371471.

2. Colen, Cynthia G, Ramey, David M. "Is breast truly best? Estimating the effects of breastfeeding on long-term child health and wellbeing in the United States using sibling comparisons." Social Science and Medicine. 109. (2014): 55-65. Print.

3. Kunz C, Rodriguez-Palmero M, Koletzko B, Jensen R. Nutritional and biochemical properties of human milk, Part I: General aspects, proteins, and carbohydrates. ClinPerinatol June 1999;26 (2): 307-33. PMID 10394490.

4. Rodriguez-Palmero M, Koletzko B, Kunz C, Jensen R. Nutritional and biochemical properties of human milk: II. Lipids, micronutrients, and bioactive factors. ClinPerinatol June 1999;26 (2): 335-59. PMID 10394491

5. Dewey KG, Heinig MJ, Nommsen LA. Maternal weight-loss patterns during prolonged lactation. Am. J. Clin. Nutr. August 1993;58 (2): 162-6. PMID 8338042.

6. Mothers and Children Benefit from Breastfeeding "Womens health.gov. 27 February 2009. Archived from the original on 16 Mar 2009.

7. Source:World Breastfeeding Week 2015 poster by WABA

8. Pisacane A, Continisio GI, Aldinucci M, D'Amora S, Continisio P. A controlled trial of the father's role in breastfeeding promotion. Pediatrics116 (4): e494-8. doi:10.1542/ peds.2005-0479. PMID 16199676.

9. Van Willigen J. Applied anthropology: an introduction. Westport, CT: Bergin \& Garvey. 2002.SBN 0-89789-833-8. 